
\section{$\square$ EMERGENCY SPECIALTY AND
BURNOUT SYNDROME IN PERUVIAN NURSES: A NATIONAL SURVEY}

\section{To the Editor:}

We have read with interest the recently published article by Zafar et al., which found that $57.1 \%$ and $56.9 \%$ of emergency physicians score high in emotional exhaustion and depersonalization dimensions, respectively, of burnout syndrome (BS) (1). In addition, emergency physicians were more likely to report higher scores of emotional exhaustion (adjusted odds ratio [aOR] 2.48; 95\% confidence interval [CI] 1.1-5.4) than other specialties (1). We would like to comment about BS and its dimensions in specialized nurses (emergency vs. others) from Peru.

We analyzed the prevalence of burnout syndrome and its scales from the National Satisfaction Survey of Health Care Users (ENSUSALUD - 2014), a public database that includes data on 5067 health professionals from 181 health facilities in 24 departments, urban and rural, in Peru (2). The sampling was probabilistic, stratified, and performed in public and private health centers. There were 2837 nurses participating in the survey; for this purpose we included only specialized nurses $(n=1446)$. We calculated the prevalence of BS and its three dimensions: emotional exhaustion (nine items), depersonalization (five items), and personal accomplishment (eight items) using the Maslach Burnout Inventory-Human Services Survey (MBI-HSS), analyzed as described by Maslach et al. (3). The results are shown in Table 1. Crude odds ratios (ORs) and aORs were calculated using logistic regression. Crude ORs were adjusted by age, work hours, salary, satisfaction, and complexity of health facility.
In total, $282(19.5 \%)$ nurses had an emergency medicine specialty, and BS prevalence was $2.8 \%$ among those nurses. Scores in emotional exhaustion $(7.1 \%$ vs. $57.1 \%$, respectively) and depersonalization (14.2\% vs. $56.9 \%$, respectively) from the emergency nurses from Peru were eight times lower than those observed by Zafar et al. in emergency physicians in Pakistan (1). Emergency nurses were more likely to report high scores in depersonalization (aOR 1.57; 95\% CI 1.04-2.35), which contrasts with the Pakistan experience.

The results of Pakistan's emergency health personnel survey show higher levels of $\mathrm{BS}$ in all dimensions compared to Peru. In part, this can be explained by the sampling, because the Peruvian survey collected a nationwide, representative sample of nurses working in 181 health facilities in different health facility sizes, whereas the sample of emergency physicians from Pakistan considered only four high-complexity hospitals with high numbers of beds. Another reason could be that Peru is one of the countries in Latin America with a lower prevalence of $\mathrm{BS}$ (4). On the other hand, whereas emotional exhaustion seems to be the main dimension of BS, in our analysis the only dimension linked with an emergency specialty was depersonalization (5). This could be explained by external variables affecting BS in health personnel, such as inappropriate work environment, low income, and variable shift work.

Even though in our results there was no significant association found between global BS, or its two dimensions (emotional exhaustion and low sense of personal accomplishment), and emergency specialty, prevalence was higher among emergency nurses. This trend is similar compared with other studies, and future interventions to reduce BS in emergency health personnel are needed (6).

Table 1. Association Between Burnout and its Dimensions with Emergency Specialty in Specialized Nurses from Peru ( $\mathrm{n}=1446)$

\begin{tabular}{|c|c|c|c|c|c|c|c|c|c|c|}
\hline & \multicolumn{2}{|c|}{ Positive* } & \multicolumn{2}{|c|}{ Negative $^{*}$} & \multirow[b]{2}{*}{ OR } & \multirow[b]{2}{*}{$95 \% \mathrm{Cl}$} & \multirow[b]{2}{*}{$p$ Value } & \multirow[b]{2}{*}{$\mathrm{aOR}+$} & \multirow[b]{2}{*}{$95 \% \mathrm{Cl}$} & \multirow[b]{2}{*}{$p$ Value } \\
\hline & $\mathrm{n}$ & $\%$ & $\mathrm{n}$ & $\%$ & & & & & & \\
\hline \multicolumn{11}{|l|}{ Burnout } \\
\hline Emergency nurses & 8 & 2.8 & 274 & 97.2 & 1.52 & $0.67-3.44$ & \multirow[t]{2}{*}{0.320} & 1.44 & $0.60-3.44$ & \multirow[t]{2}{*}{0.414} \\
\hline Other specialties & 22 & 1.9 & 1142 & 98.1 & 1.00 & Reference & & 1.00 & Reference & \\
\hline \multicolumn{11}{|l|}{ Emotional exhaustation } \\
\hline Emergency nurses & 20 & 7.1 & 262 & 92.9 & 0.98 & $0.59-1.62$ & \multirow[t]{2}{*}{0.942} & 1.15 & $0.68-1.98$ & \multirow[t]{2}{*}{0.594} \\
\hline Other specialties & 84 & 7.2 & 1080 & 92.8 & 1.00 & Reference & & 1.00 & Reference & \\
\hline \multicolumn{11}{|l|}{ Depersonalization } \\
\hline Emergency nurses & 40 & 14.2 & 242 & 85.8 & 1.49 & $1.02-2.20$ & \multirow[t]{2}{*}{0.042} & 1.57 & $1.04-2.35$ & \multirow[t]{2}{*}{0.029} \\
\hline Other specialties & 116 & 10.0 & 1048 & 90.0 & 1.00 & Reference & & 1.00 & Reference & \\
\hline \multicolumn{11}{|c|}{ Personal accomplishment } \\
\hline Emergency nurses & 63 & 22.3 & 219 & 77.7 & 1.29 & $0.94-1.77$ & \multirow[t]{2}{*}{0.114} & 1.31 & $0.95-1.82$ & \multirow[t]{2}{*}{0.102} \\
\hline Other specialties & 212 & 18.2 & 952 & 81.8 & 1.00 & Reference & & 1.00 & Reference & \\
\hline
\end{tabular}

$\mathrm{OR}=$ odds ratio; $\mathrm{Cl}=$ confidence interval.

* Cutoffs points for each dimension: emotional exhaustion $>26$, depersonalization $>9$ and personal accomplishment < 34 (2).

$\dagger$ aOR = adjusted odds ratio: age, work hours, salary, satisfaction and complexity of health facility. 
Renato Beas, BSC

Jesus Maticorena-Quevedo, BSC Alexander Anduaga-Beramendi, BSC Percy Mayta-Tristán, MD

School of Medicine Universidad Peruana de Ciencias Aplicadas Lima, Peru

http://dx.doi.org/10.1016/j.jemermed.2016.04.031

\section{REFERENCES}

1. Zafar W, Khan UR, Siddiqui SA, Jamali S, Razzak JA. Workplace violence and self-reported psychological health: coping with posttraumatic stress, mental distress, and burnout among physicians working in the emergency departments compared to other specialties in Pakistan. J Emerg Med 2016;50:167-77.

2. Instituto Nacional de Estadística e Informática (INEI). Encuesta nacional de satisfacción de usuarios del aseguramiento universal en el Perú. Lima: INEI SUNASA; 2014. [in Spanish].

3. Maslach C, Jackson SE, Leiter MP. Maslach burnout inventory manual. 3rd edn. Palo Alto, CA: Consulting Psychologists Press; 1996.

4. Grau A, Flichtentrei D, Suñer R, Prats M, Braga F. Influencia de factores personales, profesionales y transnacionales en el síndrome de burnout en personal sanitario hispanoamericano y español (2007). Rev Esp Salud Publica 2009;83:215-30. [in Spanish].

5. Maslach C, Leiter MP, Schaufeli WB. Measuring burnout. In: Cooper CL, Cartwright S, eds. The Oxford handbook of organizational well-being. Oxford: Oxford University Press; 2008:86-108.

6. Adriaenssens J, De Gucht V, Maes S. Determinants and prevalence of burnout in emergency nurses: a systematic review of 25 years of research. Int J Nurs Stud 2015;52:649-61.

\section{RESPONSE TO DR. BEAS ET AL.}

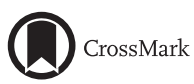

\section{To the Editor:}

We thank Beas et al. for sharing the prevalence of burnout syndrome among emergency medicine specialized nurses in Peru. They have raised an important point regarding the variation in reported prevalence of burnout syndrome among emergency care providers from different parts of the world despite the use of similar screening instruments. They have cited the work of Grau et al., which also found considerable variation in the prevalence of burnout syndrome among health care providers in several Latin American countries, ranging from 2.5\% in El Salvador to $14.4 \%$ in Argentina (1).

As we pointed out in the discussion section of our report, international reviews have tended to put the prevalence of burnout among health care providers somewhere between $30 \%$ and $60 \%$ (2). A recent U.S. study reported the overall prevalence of emotional exhaustion to be $37.9 \%$ among a large sample of U.S. physicians $(3,4)$. In that same study, the prevalence of burnout among emergency physicians was well over $60 \%$. The prevalence of burnout in some specialties is high enough to have warranted a call for action from professional groups (5).

Unfortunately, the prevalence of burnout among physicians working in the low- and middle-income countries has remained under-explored. We think that the true prevalence of burnout syndrome among Pakistani health care providers is likely to be closer to the rate we have reported (ranging between $36 \%$ and $57 \%$ for emotional exhaustion). Two recent papers from Pakistan have also found rates of burnout among medical residents that are closer to the rates we have reported $(6,7)$. Given the paucity of work on burnout among health care providers in the low- and middle-income countries, we are unable to comment on why some studies have found significantly lower rates. A better understanding of these crossnational differences is a very interesting area of inquiry and could also suggest ways to reduce the burden of burnout among frontline health care providers.

Waleed Zafar, MBBS, MSC, MPH, SCD Aga Khan University Karachi, Pakistan

http://dx.doi.org/10.1016/j.jemermed.2016.08.044

\section{REFERENCES}

1. Grau A, Flichtentrei D, Suñer R, Prats M, Braga F. Influencia de factores personales, profesionales y transnacionales en el síndrome de burnout en personal sanitario hispanoamericano y español (2007). Rev Esp Salud Publica 2009;83:215-30. [in Spanish].

2. Zafar W, Khan UR, Siddiqui SA, Jamali S, Razzak JA. Workplace violence and self-reported psychological health: coping with posttraumatic stress, mental distress, and burnout among physicians working in the emergency departments compared to other specialties in Pakistan. J Emerg Med 2016;50:167-77.

3. Shanafelt TD, Boone S, Tan L, et al. Burnout and satisfaction with work-life balance among US physicians relative to the general US population. Arch Intern Med 2012;172:1377-85.

4. Shanafelt TD, Hasan O, Dyrbye LN, et al. Changes in burnout and satisfaction with work-life balance in physicians and the general US working population between 2011 and 2014. Mayo Clin Proc 2015;90:1600-13.

5. Moss M, Good VS, Gozal D, Kleinpell R, Sessler CN. An official critical care societies collaborative statement: burnout syndrome in critical care health care professionals: a call for action. Am J Crit Care 2016;25:868-76.

6. Malik AA, Bhatti S, Shafiq A, et al. Burnout among surgical residents in a lower-middle income country - Are we any different? Ann Med Surg (Lond) 2016;9:28-32.

7. Zubairi AJ, Noordin S. Factors associated with burnout among residents in a developing country. Ann Med Surg (Lond) 2016;6:60-3. 